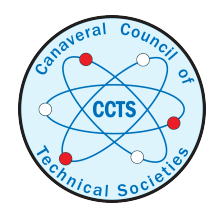

The Space Congress $®$ Proceedings

1969 (6th) Vol. 1 Space, Technology, and

Society

Apr 1st, 8:00 AM

\title{
Comparison of Measured and Theoretical Values of Electrical Conductivity in a Low Density Plasma
}

Roger M. Boatman

General Electric Co.

Follow this and additional works at: https://commons.erau.edu/space-congress-proceedings

\section{Scholarly Commons Citation}

Boatman, Roger M., "Comparison of Measured and Theoretical Values of Electrical Conductivity in a Low Density Plasma" (1969). The Space Congress ${ }^{\circledR}$ Proceedings. 3.

https://commons.erau.edu/space-congress-proceedings/proceedings-1969-6th-v1/session-1/3

This Event is brought to you for free and open access by the Conferences at Scholarly Commons. It has been accepted for inclusion in The Space Congress ${ }^{\circledR}$

Proceedings by an authorized administrator of Scholarly Commons. For more information, please contact commons@erau.edu.

EMBRYRIDDLE Aeronautical University SCHOLARLY COMMONS 


\title{
COMPARISON OF MEASURED AND THEORETICAL VALUES OF ELECTRICAL CONDUCTIVITY IN A LOW DENSITY PLASMA
}

\author{
R. M. Boatman, $\left({ }^{*}\right)$ Research Assistant \\ University of Tennessee Space Institute \\ Tullahoma, Tennessee
}

\section{Abstract}

Activities in magnetohydrodynamic power, high enthalpy wind tunnels and arc-jet engines require information and methods of calculating such properties as temperature profiles and conductivity with a plasma. While techniques are available to measure plasma temperature and electron density, no reliable formula has been available to utilize these measurements to determine plasma conductivity. An expression for electrical conductivity in low electron density plasmas has been derived, as has an expression for completely ionized gases. Neither of these expressions is appropriate to the area of current interest, moderately ionized plasmas. Extrapolation techniques have been ineffective. A new approach, based upon the work of Demetriades and Argyropoulos, utilizing a generalized Ohm's Law, was tested and found to conform most closely to experimental results. Since the validity of the experimental results are suspect, and more work should be done, the experimental work is described in some detail for the benefit of other experimentors.

\section{Introduction}

With increased interest in magnetohydrodynamic power production, high enthalpy wind tunnel facilities, and arc-jet engines, plasma diagnostics has evolved as a science in an attempt to provide knowledge of such properties as temperature profiles and electrical conductivity within a plasma. While spectroscopy and electrostatic probes can be used to obtain temperature andelectron density information, no reliable formula has been available that utilizes these measurable quantities in the gas to determine conductivity.

Previous work along this line was done for extreme cases of very slight ionization by Chapman and Cowling and complete ionization by Spitzer and Harm? Later, a combination of these two cases was suggested by Lin, Resler, and Kantrowitz ${ }^{3}$ for the intermediate ionization regions; the proposed technique consisted of adding the resistances due to the two extreme cases, with equal weighting. This method has been used but - depending on the particular case - requires large correction factors. One of the latest theories, by Demetriades and Argyropoulos, involves deriving a generalized Ohm's law from the Boltz mann equation, and this approach appears to give more reliable results over a wide range of conductivities. It is the purpose of this paper to compare conductivity values given by the various formulas avallable with a measured value obtained with a carefully calibrated, radio-frequency excited, conductivity probe in a plasma in which the properties can also be determined accurately.

A low-density, dc, arc-heated, argon plasma stream described in detail by Bryson and Frohlich ${ }^{5}$ was used for this work. A radio-frequency excited probe technique described by Sprouse ${ }^{6}$ was used to measure the conductivity in the free-jet stream and electrostatic probes of the type described by Cobine ${ }^{7}$ were used to measure electron temperature and density. Measurement of inlet gas flow rate, pressure, and temperature, together with the free-jet aerodynamics, ${ }^{8}$ made possible a determination of neutral particle number density. These data gave the necessary plasma properties for use in all the available expressions for conductivity. The other important parameter was the electron-heavy particle momentum collision cross sections, selected from available literature.

Comparison of the measured conductivity with that calculated by the four different expressions showed poor agreement in all cases. The best agreement was with the Demetriades-Argyropoulos expression. Causes for disagreement were evaluated and it was concluded that the most likely source was a small amount of ambient test cell gas that was evidently present in the argon plasma plume. These evaluations are discussed in some detail in the text.

\section{Approach}

\section{Slightly Ionized Plasma}

The electrons in a plasma are under continuous influence of the electric field; therefore, in a stationary plasma with no magnetic field applied, a drift velocity in the direction of this field and a scalar conductivity ean be defined. This drift velocity is in addition to the thermal velocity of the electron. The electron, in traversing the plasma, will collide with ions, neutral particles, and other electronics, but here only electron-neutral collisions will be considered.

To calculate the average drift velocity of the electrons, the assumption is made that the electron loses all its momentum in the direction of the field with each collision. From this basic assumption, an average drift velocity, $\bar{v}_{e}, a$ collision frequency, $v_{e}$, a diffusion constant, $D$, and finally a conductivity, $\sigma_{e n}$, can be found. A thorough treatment of this procedure is given by Whitehead. ${ }^{\ominus}$ The resultant conductivity is given by

$$
\sigma_{\text {en }}=0.625 \frac{\mathrm{N}_{e^{2}}}{N_{\mathrm{o}} Q_{e n}}\left[\frac{1}{m_{e} k T_{e}}\right]^{1 / 2}
$$

$$
\text { where: } \begin{aligned}
\sigma_{\mathrm{en}}= & \begin{array}{l}
\text { electrical conductivity considering } \\
\text { scattering by neutral particles, mho/m } \\
\text { (the "en } \\
\text { electron-neutral collisions as the domi- } \\
\text { nant process) }
\end{array} \\
\mathrm{N}_{\mathrm{e}}= & \text { electron number density, } \mathrm{m}^{-9} \\
\mathrm{~N}_{\mathrm{o}}= & \text { number density, } \mathrm{m}^{-3} \\
\mathrm{e}= & \text { electron charge, coul. } \\
\mathrm{Q}_{\mathrm{en}}= & \text { electron-neutral collision cross } \\
& \text { section, m }{ }^{2} \\
\mathrm{~m}_{\mathrm{e}}= & \text { electron mass, } 9.108 \times 10^{-31} \mathrm{~kg} \\
\mathrm{k}= & \text { Boltzmann's constant, } 1.380 \times 10^{-23} \\
& \text { joule/ }{ }^{\circ} \mathrm{K} \\
\mathrm{T}_{\mathrm{e}}= & \text { electron temperature, }{ }^{\circ} \mathrm{K}
\end{aligned}
$$


While Whitehead used the simple kinetic theory of gases and elementary statistical mechanics, a rigorous derivation given by Chapman and Cowling ${ }^{1}$ results only in a slight change in the constant coefficient to 0.532 .

\section{Fully Ionized Plasma}

In a fully ionized gas, the assumptions above are not valid due to the nature of the impeding force, which now depends upon the solution of electron-electron and electron-ion collision problems. Spitzer and Harm ${ }^{2}$ solved this problem and found that the conductivity is given by

$$
\sigma_{e i}=0.591 \frac{\left(4 \pi \epsilon_{0} k T_{e}\right)^{2}}{\left(m_{e} k T_{e}\right) 1 / 2 e^{2}} \frac{1}{\ln \Lambda}
$$

where: $\quad \sigma_{\mathrm{ei}}=$ electrical conductivity considering scattering by ions, mho/m

$\mathrm{m}_{\mathrm{e}}=$ electron mass, $9.108 \times 10^{-31} \mathrm{~kg}$

$\mathrm{k}=$ Boltzmann's constant, $1.380 \times 10^{-23}$ joule $/{ }^{\circ} \mathrm{K}$

$\mathrm{T}_{\mathrm{e}}=$ electron temperature, ${ }^{\circ} \mathrm{K}$

e = electron charge, coul.

$\epsilon_{0}=$ dielectric constant, $10^{-3} / 36 \pi \mathrm{farad} / \mathrm{m}$

$\Lambda=$ interaction parameter

The "ei" has been added to indicate electron-ion collisions as the dominant process. The interaction parameter, $\Lambda$, is the ratio of the Debye shielding distance in the plasma to the impact parameter for 90 degree particle scattering, and is given by

$$
\Lambda=\frac{12}{\mathrm{e}^{3}}\left[\frac{\left(\mathrm{\sigma}_{\mathrm{o}} \mathrm{T}_{\mathrm{e}}\right)^{3}}{2 \mathrm{~N}_{\mathrm{e}}}\right]
$$

where: $\Lambda$ interaction parameter

$\epsilon_{0}=$ dielectric constant, $10^{-9} / 36 \pi \mathrm{farad} / \mathrm{m}$

$\mathrm{e}=$ electron charge, coul.

$\mathrm{N}_{\mathrm{e}}$ = electron number density, $\mathrm{m}^{-3}$

$k^{e}=$ Boltzmann's constant, $1.380 \times 10^{-23}$ joule/ ${ }^{\circ} \mathrm{K}$

$\mathrm{T}_{\mathrm{e}}=$ electron temperature, ${ }^{\circ} \mathrm{K}$

Intermediate Ionized Plasma

It must be noted at this juncture that each of the methods thus far discussed involve either slightly ionized gas or completely fonized gas. Since both interaction phenomena can occur in plasmas dealt with in the laboratory, a more comprehensive technique is needed.

For an arbitrary degree of ionization, a procedure has been proposed by Lin, Resler and Kantrowitz, ${ }^{3}$ They proposed that the impedance to electron flow, due to neutral particles and ions, should be additive; that is,

$$
\frac{1}{\sigma}=\frac{1}{\sigma_{\text {en }}}+\frac{1}{\sigma_{\text {ef }}}
$$

Recently, a method has been developedby Demetriades and Argyropoulos, in which they derive a generalized Ohm's Law. ${ }^{4}$ Only the results of this deve topment will be stated here. The first approximation to the electrical conductivity is $\sigma$, and the second approximation, including electron-electron interactions can be written as

$$
\sigma=\frac{\sigma_{0}}{\left(1-\Delta^{\prime}\right)}
$$

$\sigma_{0}$ is defined in terms of the time averaged, velocity dependent collision cross section, the electron temperature, and the electron number density; that is,

$$
\sigma_{0}=3 / 4 \frac{\mathrm{N}_{\mathrm{e}} \mathrm{e}^{\mathrm{E}}}{\mathrm{m}_{\mathrm{e}}\left(\frac{8 \mathrm{kT}_{\mathrm{e}}}{\pi \mathrm{m}_{\mathrm{e}}}\right)^{1 / 2}} \frac{1}{\sum_{\mathrm{s} \neq \mathrm{e}}^{\mathrm{N} \mathrm{N}_{\mathrm{e}} \mathrm{es}}}
$$

where:

$$
\begin{aligned}
& \sum_{s \neq e} N_{S} Q_{e s}=N_{i} Q_{e i}+N_{n} Q_{e n} \\
& N_{e}=\text { electron number density, } \mathrm{m}^{-3} \\
& e \quad=\text { electron charge, coul. } \\
& m_{e}=\text { electron mass, } 9.108 \times 10^{-31} \mathrm{~kg} \\
& \mathrm{k} \quad=\quad \text { Boltzmann's constant, } 1.380 \times 10^{-20} \\
& \quad \text { joule/ }{ }^{\circ} \mathrm{K} \\
& \mathrm{T}_{\mathrm{e}}=\text { electron temperature, }{ }^{\circ} \mathrm{K} \\
& \mathrm{N}_{\mathrm{i}}=\text { ion number density, } \mathrm{m}^{-3} \\
& \mathrm{Q}_{\mathrm{ei}}=\text { electron-ion collision cross section, } \mathrm{m}^{2} \\
& \mathrm{Q}_{\mathrm{en}}=\text { electron-neutral collision cross } \\
& \quad \text { section, m } \\
& \mathrm{N}_{\mathrm{n}}=\text { number density, } \mathrm{m}^{-3}
\end{aligned}
$$

Subscripts "en" and "ci" are defined above. The correction function for $\sigma_{0}, \Delta '$, is defined in terms of the above mentioned collision cross sections and quantities for interactions between particles " $e$ " and "s", which shall be represented by $A_{e s}{ }^{(5)}$ and $A_{e s}{ }^{(2)} ; 1$. e.,

$$
\Delta^{\prime}=\frac{2 \cdot 5 \sum_{S \neq e}\left(A_{e s}(2) N_{s} Q_{e s}\right)^{2} / \sum_{S \neq e} N_{S} Q_{e s}}{\frac{2 \sqrt{2}}{5}\left[1-(2 \ln 1)^{-1}\right] N_{e} Q_{e i}+\sum A_{e s}(5) N_{s} Q_{e s}}
$$

with the following definitions:

$$
\begin{aligned}
& \Lambda=3 \lambda\left(\frac{4 \pi \epsilon_{\mathrm{n}}}{\mathrm{e}^{2}}\right) \mathrm{kT}_{\mathrm{e}} \\
& \lambda^{-2}=\frac{1}{\epsilon_{0}}=\frac{\mathrm{N}_{\mathrm{s}} \mathrm{e}_{\mathrm{s}}^{\mathrm{e}}}{\mathrm{kT} \mathrm{e}} \\
& \mathrm{Q}_{\mathrm{ei}}=\pi / 2\left(\frac{\mathrm{e}^{2}}{4 \pi \epsilon_{\mathrm{o}}} \frac{1}{\mathrm{kT}_{\mathrm{e}}}\right)^{2} \ln \cdot 1
\end{aligned}
$$


*(Continued)

Calculated $Q_{e s}$, Aes ${ }^{(2)}$, and $A_{e s}{ }^{(5)}$ were all obtained by a numerical integration process using velocity dependent cross sections as recommendedby Devoto. ${ }^{10}$ Aes for the first three columns were determined by Garrison. ${ }^{11}$

\section{Experimental Work}

To make a valid comparison between theory and measurement, an experiment was designed that would allow accurate conductivity measurements to be made simultaneously while measuring necessary plasma parameters. The following apparatus was used to give these data.

\section{Test Cell}

The are-jet plasma source was enclosed in a 12-inch diameter, water-jacketed metal test cell (Figure 1) which was pumped to approximately 0.5 torr by two mechanical vacuum pumps. The jet was mounted vertically, with quartz windows located on two sides to provide visual access to the area of the plasma under study. The electrical probes were mounted and positioned through a third window made of plexiglass.

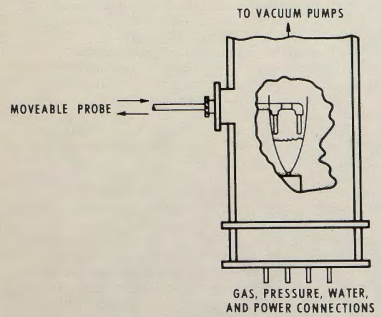

Figure 1. Schematic of Test Cell

\section{Plasma Jet}

The arc-jet plasma source (Figure 2) used for the experiments described herein consisted of a $1 / 2$-inch tungsten-tipped cathode mounted in a ceramic cylinder test body, and concentric with a copper anode having a 1/4-inch diameter orifice. Both were water cooled and neither showed significant erosion after several hours of use. Typical operating conditions were as follows:

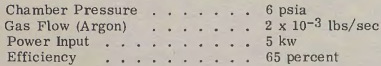

The efficiency of the plasma jet is defined as the percentage of input power that is not carried away in the enoling water after a stable operating point has been reached. The operating characteristics of this arc-jet were determined and fully described by R.J. Bryson.

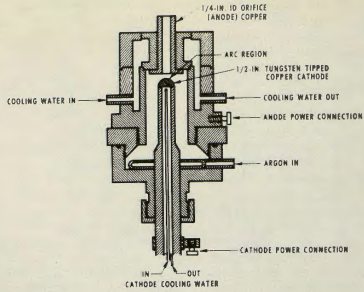

Figure 2. Schematic of Arc Jet Cross Section

\section{Plasma Description}

The dc, arc-generated argon plasma exhausts from a chamber at atmospheric pressure through a $1 / 4$-inch orifice into a low pressure ( 1 torr) test cell with a plume which extends approximately 1 meter downstream from the orifice exit. The stream is characterized by two distinct regions: (1) a brightly radiating core extending about 1 centimeter from the exit, and (2) a weakly radiating supersonic stream which expands into the plume illustrated in Figure 3.

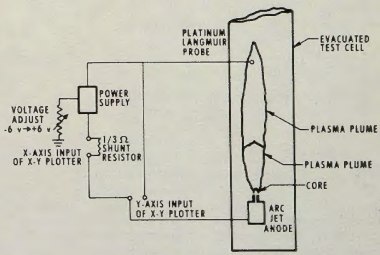

Figure 3. Schematic of Langmuir Probe Instrumentation

The intensely radiating core is attributed to the blown are process as described by Dooley;, McGregor, and Brewer ${ }^{12}$ and to spontaneous decay of excited atoms formed in the arc. Many of the properties of the plasma can be qualitatively explained by considering the dwell time of the molecules in the arc. That is, the arc exists at the most dense region of gas flow, and because of the high velocity of the gas at this point, the molecules are not in the are long enough to gain the energy available through collisions with the electrons. This results in a large difference between gas te mperature $\left(3000^{\circ} \mathrm{K}\right)$ and electron temperature $\left(18,000^{\circ} \mathrm{K}\right)$.

In the expansion process of the gas from the relatively high pressure of the arc region to the low test cell pressure, the gas temperature drops to approximately $100^{\circ} \mathrm{K}$ 
and the electron temperature drops to about $4000^{\circ} \mathrm{K}$. This expansion process is described by Chou and Talbot ${ }^{23}$ and has been attributed to the existence of a superthermal population of metastable atoms in the stream which are further excited through electron collision. ${ }^{14}$

\section{Conductivity Probe}

The radio frequency probe system consisted of an oscillator with a mechanically swept resonant circuit consisting of the probe coil and a variable capacitor. Briefly, the principle upon which the radio frequency probe depends is as follows. As the probe circuit is swept through the crystal resonant frequency, the oscillator voltage amplitude at the plate increases as long as the load, approaching resonance, as seen by the oscillator is inductive. At the point where the load becomes capacitive the oscillator drops out of oscillation, producing a sharp trailing edge and a reliable reference point that indicates the instant in time at which the circuit was resonant at the crystal frequency. The amplitude of the signal at the plate of the oscillator at resonance is determined by the $Q$ of the tank circuit. If the coil of the tank circuit is immersed in a conductive media, the $Q$ of the coil is lowered; hence, the radio frequency voltage is lower. The coil was calibrated by placing it in regions of known conductivity and plotting the calibration curve shown in Figure 4. This method is thoroughly discussed by Sprouse.

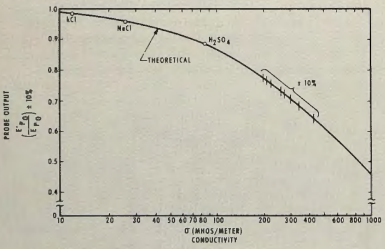

Figure 4. Calibration Curve For Coil 1

Following the oscillator circuit was a standard envelope detector circuit whose output fed a photographic type chart recorder. The coil was mounted in an Alumina probe body, supported by a water-cooled copper housing (Figures 5 and 6) which was inserted into the center of the plasma stream.

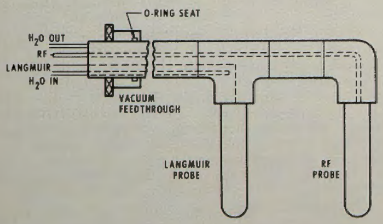

Figure 5. Schematic of Probe Housing

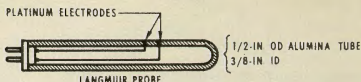

LANGMUIR PROBE

45 TURNS \#22 ENAMEL WIRE

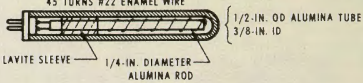

RADIO FREQUENCY EXCITED PROBE

Figure 6. Cross Sectional Diagram of Probes

\section{Langmuir Probe}

A Langmuir probe was used to measure electron temperature and electron number density. This probe was mounted in an Alumina body, identical to the RF probe, with a plane platinum electrode that is oxidation resistant. This probe was connected through a low impedance power supply to the anode of the plasma source (Figure 3 ). The theory of the probe is based on the assumption that a space charge sheath surrounding the probe exists, in which the entire electric field due to the applied potential is confined. If we assume the sheath is thin and constant in thickness, and there are no collisions within the sheath, electrons that strike the sheath boundary and have sufficient energy to overcome the potential applied to the probe also reach the probe and are accounted for in the measurement of probe current. This theory has been found to be valid for plane probes of sufficient sizc that edge effects of the sheath are negligible.

For the plane probe immersed in a plasma with a.1 applied electric field, the slope of a linc Iep (probc current) versus $V_{p}$ (probe potential) is $e / k T_{e}$ and $T_{e}$ can he calculated. By use of this value $\mathrm{T}_{e}, \mathrm{~N}_{\mathrm{e}}$ can be determined directly from the saturation probe current. The instrumentation shown in Figure 3 was used to obtain data such as the curve illustrated in Figure 7 , and then replotted on semilog paper, as shown in Figure 8. For a detailed treatment, see Cobine. Typical probe clata viclded electron number densities of the order $2 \times 10^{20} / \mathrm{m}^{3}$. The same curves (Figures 7 and 8 ) were used to determinc electron temperatures of the order of $4 \times 10^{3{ }^{a}} \mathrm{~K}$.

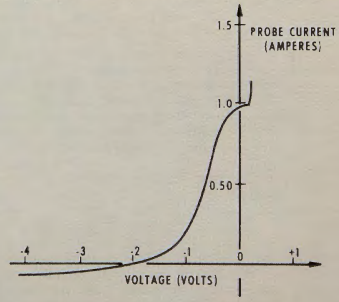

Figure 7. Langmuir Probe Curve 


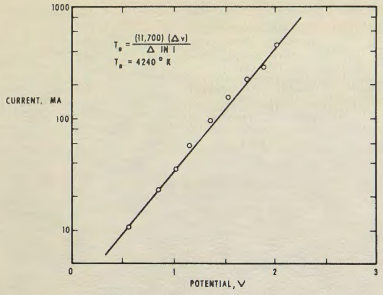

Figure 8. Log Plot For Electron

Temperature Measurement

\section{Procedure}

The plasma characteristics were obtained as follows: The arc-jet was started, and the gas flow rate and input power were set. After steady-state operation was reached (about 1 minute), the operating parameters were measured. With gas conditions known, the electrical measurements were then taken, starting with the radio-frequency probe. The radio-frequency probe was immersed in the stream and, with a sweep rate of 3 cycles per second, the RF envelope voltage was recorded on the oscillograph. Without changing any parameters, the Langmuir probe was now immersed in the flow and a curve of $V_{p}$ vs $I_{p}$ plotted on the $\mathrm{X}-\mathrm{Y}$ recorder in order to determine electron temperature and electron number density. Once again, to assure that plasma conditions had not changed, the radio-frequency probe was placed back in the stream and another set of control data obtained. This procedure was repeated for different input power levels so that a range of conductivities could be examined. The input power range for these experiments was from 4.4 to 5.4 kilowatts.

The gas conditions were established from monitor gauges. Once a static pressure and the temperature at the jet orifice were obtained, a computer program mapped the flow field and permitted determination of neutral number density in the region of the probe. ${ }^{8}$ Typical neutral densities obtained in this manner were of the order of $5.8 \times 10^{22} / \mathrm{m}^{3}$.

\section{Results and Comparison}

The results of this experiment are tabulated in Table 1. The three separate trials were performed at different power levels to provide a spread of conductivities. The five rows of computed conductivity were based on the method indicated at the left of each row.
The major source of error in the above measurements was the collision cross section for electron-neutral interaction. The values used in the numerical integration were selected from the latest, best documented source available. ${ }^{10}$ Other error sources came from measuring equipment, such as measuring relative peak heights for the RF probe and in measuring the gas content of the cell. The overall accuracy of the measured values is considered good, especially in the light of current plasma analysis techniques.

\section{Conclusions}

Considering the fact that the Chapman-Cowling formula and the Spitzer-Harm formula were derived for extreme conditions, it is not surprising to find a discrepancy between these and the measured value. The value obtained with the Kantrowitz formula is the currently most widely used and differs by a percentage not uncommon for this region. Correction factors are employed with this formula to give a reasonable value.

The equations derived by Demetriades and Argyropoulos were used for the computation in the last two rows of Table 1, with the first approximation and the second approximation listed, respectively. The first approximation gave results well within the range of error encountered in the data available for the collision cross section of argon.

It is well to note at this time that Table 1 indicates the inadequacy of the first three methods for calculating the conductivity. However, since these three methods depend on extreme conditions or some combination of the extremes, the inadequacy is to be expected. The more complex expression of Demetriades and Argyropoulos is a step in the right direction, but a discrepancy still exists between the measured and calculated values. The one term that was not measured, and is tenuous at best, is the electron-neutral collision cross section.

It has been noticed previously in studies performed on a similar argon plasma (Brewer and McGregor) ${ }^{24}$ that ambient test cell gases mix in the region of the plume containing the probe. Because the collision cross section for electron-neutral interaction in nitrogen, for instance, is two orders of magnitude greater than argon cross sections for the same interactions, as little as one percent mixing would make a factor of two difference in the conductivity for the first approximation, as can be seen from equation (12).

$$
\underset{s \neq e}{\Sigma} N_{s} Q_{e s}=N_{e} Q_{e i}+N_{n} Q_{e n}+N_{n}^{\text {(Nitrogen) }} Q_{e n}^{\text {(Nitrogent }}
$$

It is recommended by the author that further work be done in this area; namely, that a probe be designed whereby the constituents of the gas may be measured simultaneously with the other measured parameters used in this work. 
TABLE 1

EXPERINENT RESULTS

\begin{tabular}{|c|c|c|c|}
\hline & Run No. 1 & Run No. 2 & Run No. 3 \\
\hline $\begin{array}{l}\quad 1 \\
\text { Measured } \\
\text { Conductivity } \\
\text { mho }-\mathrm{m}^{-1}\end{array}$ & 210 & 235 & 263 \\
\hline $\begin{array}{l}\quad 2 \\
\text { Electron Number } \\
\text { Density } \\
\mathrm{m}^{-3}\end{array}$ & $1.70 \times 10^{20}$ & $1.84 \times 10^{20}$ & $2.61 \times 10^{2}$ \\
\hline $\begin{array}{l}\quad 3 \\
\text { Electron } \\
\text { Temperature } \\
{ }^{\circ} \mathrm{K}\end{array}$ & 3550 & 4240 & $4 \times 25$ \\
\hline $\begin{array}{l}\quad \stackrel{4}{\text { Neutral Number }} \\
\text { Density } \\
\mathrm{m}^{-3}\end{array}$ & $5.85 \times 10^{22}$ & $5.85 \times 10^{2 \bar{e}}$ & $5.85 \times 10^{22}$ \\
\hline $\begin{array}{l}\quad 5 \\
\text { Chapman-Cowling } \\
\text { mho }-m^{-1}\end{array}$ & $2,46 \times 10^{4}$ & $2.16 \times 10^{4}$ & $2.57 \times 10^{4}$ \\
\hline $\begin{array}{l}\quad 6 \\
\text { Spitzer-Harm } \\
\text { mho }-m^{-1}\end{array}$ & 609 & 739 & R95 \\
\hline $\begin{array}{l}\quad 7 \\
\text { Kantrowitz, et al } \\
\text { mho }-\mathrm{m}^{-1}\end{array}$ & 594 & 714 & 865 \\
\hline $\begin{array}{l}\quad 8 \\
\text { Demtriades- } \\
\text { Argyropoulos } \\
\text { (First Approximation) } \\
\text { mho - } \mathrm{m}^{-1}\end{array}$ & 300 & 365 & 444 \\
\hline $\begin{array}{l}\quad 9 \\
\text { Demetriades- } \\
\text { Argyropoulos } \\
\text { (Second Approximation) } \\
\text { mho - } \text { m }^{-1}\end{array}$ & 572 & 712 & 845 \\
\hline
\end{tabular}


1. Chapman, S. and Cowling, T. G. The Mathematical Theory of Non-Uniform Gases. Cambridge: Cambridge University Press, 1958.

2. Spitzer, L. and Harm, R. "Transport Phenomena in a Completely Ionized Gas," Physical Review, 89 (No. 5) :977-981, March 1953.

3. T.in, S. C., Resler, E. L., and Kantrowitz, A. "Electrical Conductivity of Highly Ionized Argon Produced by Shock Waves," Journal of Applied Physics, 26:1, January 1955.

4. Demetriades, S. T. and Argyropoulos, G.S. "Ohm's Law in Multicomponent Non-Isothermal Plasmas with Temperature and Pressure Gradients, "STD Research Corporation Report STF-65-12, Pasadena, California September 1965 .

5. Bryson, R. J. and Frohlich, J. P. "Study of the Energy Addition Process in a D-C Arc Jet," Arnold Engineering Development Center Report TR-15-268, Arnold Air Force Station, Tennessee, April 1966.

6. Sprouse, J. A "Coupling Mechanisn Between Radio Frequency Excited Coils and Conductive Media," Unpublished Masters thesis, University of Tennessee, Knoxville, June 1967 .

7. Cobine, J.D. Gaseous Conductors. New York: Dover Publications, 1958.
8. Bauer, R. C. Private Communication. Arnold Engineering Development Center, Arnold Air Force Station, Tennessee.

9. Whitehead, G.L. "Equations for Electrical Conductivity of Air Nitrogen, and Combustion Gas Products, " Unpublished Masters thesis, University of Tennessee, Knoxville, December 1967.

10. Devoto, R.S. "Transport Coefficients of Partially Ionized Argon," The Physics of Fluids, 10:2, February 1967.

11. Garrison, G.W. "Electrical Conductivity of a Seeded Nitrogen Plasma," ALAA Paper 67-716,

AIAA, New York, New York, 1967.

12. Dooley, M. T., McGreg»r, W. K, , and Brewer, L. E. "Characteristics of the Arc in a Gerdien-Type Plasma Generator," Arnold Engineering Development Center Repurt TR-1i1-13, Arnold Air Force Station, Tenne-see, December 1961.

13. Chou, Y.S, and Talbot, L. "Source-Flow Expansion of a Partially Ionized Gas into a Vacuum," AIAA Journal, 5:2166i-2172, December 1967.

14. Brewer, L.E. and Meciregor, W. K. "Excitation of Nitrogen by Metastable Argon Atoms," The Physics of Fluids, 5:11, November 1962. 